\title{
Adsorption of Congo Red from Aqueous Solution Using CTAB-Kaolin from Bechar Algeria
}

\author{
Mohamed Amine Zenasni ${ }^{1,2}{ }^{*}$, Bahia Meroufel ${ }^{1,2}$, André Merlin², Béatrice George ${ }^{2}$ \\ ${ }^{1}$ Laboratory of Valorisation of Vegetal Resources and Food Security (VRVSA), Bechar University, Bechar, Algeria \\ ${ }^{2}$ Laboratory of Studies and Research on Material Wood (LERMAB), University of Lorraine, Nancy, France \\ Email: ${ }^{2}$ am.zenasni@gmail.com
}

Received 22 July 2014; revised 28 August 2014; accepted 17 September 2014

Copyright $(\underset{2014}{ } 2 \mathrm{by}$ authors and Scientific Research Publishing Inc.

This work is licensed under the Creative Commons Attribution International License (CC BY).

http://creativecommons.org/licenses/by/4.0/

(c) (i) Open Access

\begin{abstract}
Cetyltrimethylammonium bromide-modified kaolin (CTAB-kaolin or KC) was prepared and tested as an adsorbent for an anionic dye Congo red (CR) removal from aqueous solution in comparison with natural kaolin $(\mathrm{K})$. The effect of various experimental parameters was investigated using a batch adsorption technique. In this manner, the adsorption isotherms and adsorption kinetics of CR on $\mathrm{K}$ and $\mathrm{KC}$ were examined. The isothermal data could be well described by the Langmuir equation and the dynamical data fit well with the pseudo-second-order kinetic model. The adsorption capacity of modified kaolin KC $(24.46 \mathrm{mg} / \mathrm{g})$ was found to be around 4 times higher than that of natural kaolin $\mathrm{K}(5.94 \mathrm{mg} / \mathrm{g})$. The $\mathrm{KC}$ demonstrated the highest adsorption capacity by removing over $98 \%$ of CR after ten minutes of contact. These results indicate that CTAB-kaolin could be employed as low-cost alternative to activated carbon in wastewater treatment for the removal of colour which comes from industrial effluents of textile activities, tanning or printing.
\end{abstract}

\section{Keywords}

Adsorption, Congo Red Dye, Surfactant, Kaolin, Kinetics

\section{Introduction}

The wastewater disposed by textile industries is causing major hazards to the environment and drinking water due to presence of a large number of contaminants like acids, bases, toxic organic, inorganic, dissolved solids and colour [1]. In effect, the discharge of contaminants such as dyes in the environment is worrying for both

${ }^{*}$ Corresponding author.

How to cite this paper: Zenasni, M.A., Meroufel, B., Merlin, A. and George, B. (2014) Adsorption of Congo Red from Aqueous Solution Using CTAB-Kaolin from Bechar Algeria. Journal of Surface Engineered Materials and Advanced Technology, 4, 332341. http://dx.doi.org/10.4236/isemat.2014.46037 
toxicological and esthetical reasons as damaging the quality of the receiving streams and is toxic to food chain organisms [2]. These colored compounds are not only aesthetically displeasing but also inhibiting sunlight into the stream and reducing the photosynthetic reaction. Since many organic dyes are harmful to human beings, the removal of colour from waste effluents becomes environmentally important [3].

Congo red (CR) is a highly water-soluble diazo dye. It is an anionic acid dye used as a laboratory aid in testing for free hydrochloric acid in gastric contents, in the diagnosis of amyloidosis, as an indicator of $\mathrm{pH}$, and also as a histological stain for amyloid. It has a strong affinity to cellulose fibers and thus is employed in textile industries. It is a derivative of benzidine and napthoic acid and metabolizes to carcinogenic products [4]. It is investigated as a mutagen and reproductive effector. It is a skin, eye, and gastrointestinal irritant. It may affect blood factors such as clotting, and induce somnolence and respiratory problems [5]. Therefore, an increased interest has been focused on removing of such dyes from the wastewater. Various physical, chemical and biological methods, including adsorption, biosorption, ozonation, coagulation/flocculation, advanced oxidation, membrane filtration and liquid-liquid extraction have been widely used for the treatment of dye-bearing wastewater [6]-[9]. Adsorption is a very effective separation technique and now it is considered to be superior to other techniques for water treatment in terms of initial cost, simplicity of design, ease of operation and insensitive to toxic substances [10]-[13]. A commonly-used adsorbent, activated carbon has a high capacity for the removal of dye/organics [14] [15]. But some of its disadvantages are the high price of treatment and difficult to regenerate which gives the increase in cost of the wastewater treatment. Consequently this cost problem has led to a search for cheap and efficient alternate materials including clays such as bentonite, sepiolite montmorillonite, alunite, and kaolinite [16]-[19]. In addition, clay minerals can be modified by either impregnation or grafting of organic/inorganic molecules on its surface to improve its properties, for example, bentonite or montmorillonite was modified with various quaternary ammonium cations for the removal of various organic contaminants from water and wastewater [20]-[22]. Kaolinite clays were also modified with tri-polyphosphate [23] [24], and 2-mercaptobenzothiazole impregnated clay surface was used for the removal of some heavy metal ions from water samples [25].

In this work, we modified kaolin with cetyltrimethylammonium bromide (cationic surfactant) to investigate kinetics and the mechanism of adsorption of Congo red dye onto organoclay (CTAB-kaolin). Comparative studies on the adsorption capacities of CR on both supports modified kaolin and kaolin was also established. Langmuir and Freundlich equations were used to determine the isotherm which gives the best correlation with experimental data. Pseudo-second-order model was used to evaluate the adsorption kinetics for both adsorbents.

\section{Materials and Methods}

\subsection{Clay Minerals}

Kaolin used was collected from a natural deposit, located in Tabelbala in province Bechar (Algeria). The average surface area and CEC of kaolin which were measured using methylene blue technique were $10.60 \mathrm{~m}^{2} / \mathrm{g}$ and 8.01 meq/100g, respectively [18].

\subsection{Reagents}

Cetyltrimethylammonium bromide (CTAB) used for CTAB-kaolin (KC) preparation was of analytical grade and was purchased from Aldrich Chemical. Its chemical formula is $\left(\mathrm{C}_{16} \mathrm{H}_{33}\right) \mathrm{N}\left(\mathrm{CH}_{3}\right)_{3} \mathrm{Br}$ with molecular weight of $363.9 \mathrm{~g} / \mathrm{mol}$.

The Congo red obtained from Fluka, was used as received without any purification. The chemical formula of CR is $\mathrm{C}_{32} \mathrm{H}_{22} \mathrm{~N}_{6} \mathrm{Na}_{2} \mathrm{O}_{6} \mathrm{~S}_{2}$ with Colour Index 22120 and molecular weight of $696.663 \mathrm{~g} / \mathrm{mol}$. The chemical structures of the dye and CTAB are given in Figure 1.

\subsection{Instrumentation}

The $\mathrm{pH}$ of all solution was measured by a Titra Lab Instrument TIM800 Model pH meter. Congo red concentrations of solutions before and after adsorption were measured using a UV-VIS spectrophotometer (UV.1700 Pharmrspac) at wavelengths of $497 \mathrm{~nm}$ which corresponds to the maximum absorbance of the dye. The Fourier transform infrared (FT-IR) absorption spectra was recorded on $\mathrm{KBr}$ pressed pellets of the powdered sample in the range $4000-400 \mathrm{~cm}^{-1}$, using a PerkinElmer FTIR 2000 spectrophotometer and the thermal analyses were performed using SETARAM SETSYS thermogravimetric apparatus. 


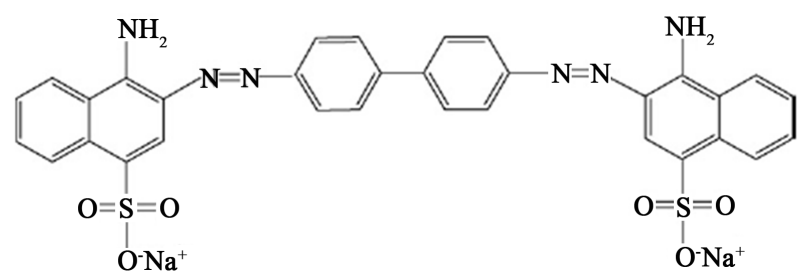

(a)

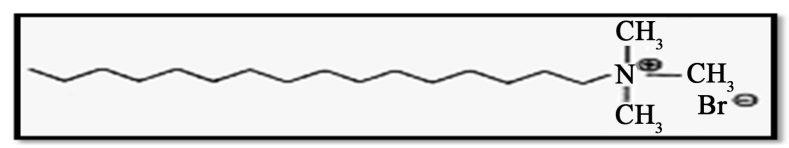

(b)

Figure 1. (a) Structure of CR; (b) Structure of CTAB.

\subsection{Pre-Treatment and Organofunctionalization of Kaolin}

Kaolin was initially saturated by ion exchange with excess sodium to eliminate the original cations from the interlayer region. Then, $20 \mathrm{~g}$ of kaolin was reacted with $500 \mathrm{~mL}$ of $\mathrm{NaCl} 1 \mathrm{~N}$ for $24 \mathrm{~h}$ at $343 \mathrm{~K}$. The sodium kaolin $\left(\mathrm{KNa}^{+}\right)$was separated using centrifugation and washed in distilled water until no residual halogen anions were detected by adding a $0.1 \mathrm{~mol} \cdot \mathrm{L}^{-1}$ of silver nitrate $\left(\mathrm{AgNO}_{3}\right)$ solution to the filtrate. The solid was dried at $373 \mathrm{~K}$ [26].

For CTAB-kaolin (KC) preparation, $10 \mathrm{~g}$ sample of the dried $\mathrm{KNa}^{+}$was added to $200 \mathrm{~mL}$ of distilled water containing $0.3 \mathrm{~g}$ of CTAB. The suspension was then shaken, at $70^{\circ} \mathrm{C}$, for $24 \mathrm{~h}$. The treated clay was then washed by shaking with $250 \mathrm{~mL}$ of water. The washing process was repeated several times until the washings were free from bromide ions as indicated by $\mathrm{AgNO}_{3}$. The organokaolin was at last separated from water by centrifigation, dried at $80^{\circ} \mathrm{C}$ and gently ground with a mortar and pestle to break up aggregate particles [22].

\subsection{Adsorption}

Adsorption for CTAB-kaolin was undertaken in a batch equilibrium technique. The batch sorption studies were performed using different times of contact, initial concentrations of the dye and $\mathrm{pH}$ values. The effect of contact time on the adsorption capacity of modified kaolin was studied in the range 1 - $100 \mathrm{~min}$ at an initial concentration of $100 \mathrm{mg} / \mathrm{L}$. Adsorption kinetics was studied using an initial concentration of $100 \mathrm{mg} / \mathrm{L}$ with the adsorbent dosage of $0.1 \mathrm{~g} / 10 \mathrm{~mL}$ at $\mathrm{pH}$ 6.9. Adsorption isotherms were studied at various initial concentrations of CR dye. The effect of $\mathrm{pH}$ was observed by studying the adsorption of the dye over a $\mathrm{pH}$ range of $5-13$. The $\mathrm{pH}$ of the solution was adjusted with $\mathrm{NaOH}$ or $\mathrm{HCl}$ solutions. The amount of dye adsorbed per unit mass of CTAB-kaolin was calculated by using the mass balance equation given in Equation (1) [27].

$$
q_{e}=\frac{\left(C_{0}-C_{e}\right) V}{m}
$$

where $q_{e}$ is the maximum adsorption capacity in $\mathrm{mg} / \mathrm{g}, C_{0}$ is the initial concentration and $C_{e}$ is the concentration at equilibrium of CR dye solution in $\mathrm{mg} / \mathrm{L}, V$ is the volume of the $\mathrm{CR}$ solution in $\mathrm{mL}$ and $m$ is the mass of modified kaolin in grams.

The sorption capacity at time $t, q_{t}(\mathrm{mg} / \mathrm{g})$ was obtained as Equation (2) [27]:

$$
q_{t}=\frac{\left(C_{0}-C_{t}\right) V}{m}
$$

where $C_{0}$ and $C_{t}(\mathrm{mg} / \mathrm{L})$ are the liquid phase concentrations of CR at initial and a given time $t, V$ is the solution volume and $m$ the mass CTAB-kaolin (g).

The percent adsorption of dye was calculated as follows Equation (3) [28]:

$$
\text { Sorption } \%=\frac{C_{0}-C_{e}}{C_{0}} \times 100 \%
$$

The same procedure was adopted to determine the retention of the dye on natural kaolin (K) [18]. 


\section{Results and Discussion}

\subsection{Characterization of Modified Kaolin}

\subsubsection{FTIR Analysis}

The presence of organic molecules in the clay layers can be determined by using infrared spectroscopy followed by TG.

In order to obtain complementary evidence for the intercalation of quaternary alkylammoniumcations into the silicate lattice, FTIR spectra were recorded in the region $400-4000 \mathrm{~cm}^{-1}$ (see Figure 2). New absorption band in spectrum of KC was detected around $3014 \mathrm{~cm}^{-1}$ which is due to stretching vibrations of $\mathrm{CH}_{3}-\mathrm{N}$. The symmetric and asymmetric stretching vibrations of methyl groups $\left(\mathrm{CH}_{3}\right)$ and the methylene $\left(\mathrm{CH}_{2}\right)$ of the aliphatic chain of the surfactant appear more strongly at $2850 \mathrm{~cm}^{-1}$ and $2920 \mathrm{~cm}^{-1}$ [29]. Additionally, the bending vibration of the methylene groups can be observed at $1467 \mathrm{~cm}^{-1}$. A peak can be observed at $1394 \mathrm{~cm}^{-1}$ that arises from the $\mathrm{C}-\mathrm{N}$ group of the organic modifier, verifying the intercalation of surfactant molecules between the silicates. The characteristic bands of the C-N bond which are between 910 and $1000 \mathrm{~cm}^{-1}$ (very strong for compounds of the type $\left.\mathrm{R}-\mathrm{N}^{+}\left(\mathrm{CH}_{3}\right)_{3}\right)$ are hidden in complex inorganic-clay, by deformation vibrations of Al-OH $\left(926 \mathrm{~cm}^{-1}\right)$.

\subsubsection{TG Analysis}

The TG curve of natural kaolin K (Figure 3) suggested a loss of mass over the temperature of $63^{\circ} \mathrm{C}-205^{\circ} \mathrm{C}$, which was attributed to the loss of adsorbed water, and an additional loss over the temperature range of $450^{\circ} \mathrm{C}$ -

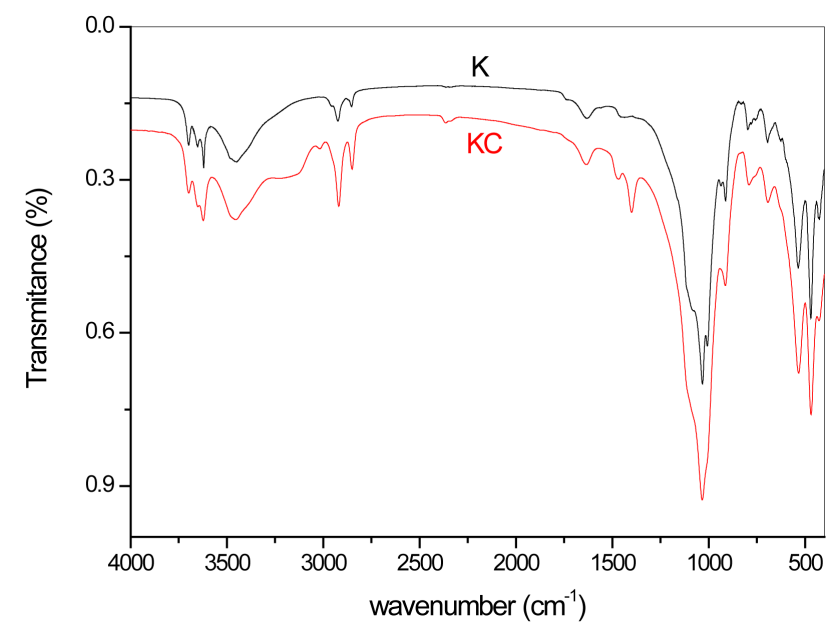

Figure 2. IR spectra of CTAB-kaolin (KC) and kaolin (K).

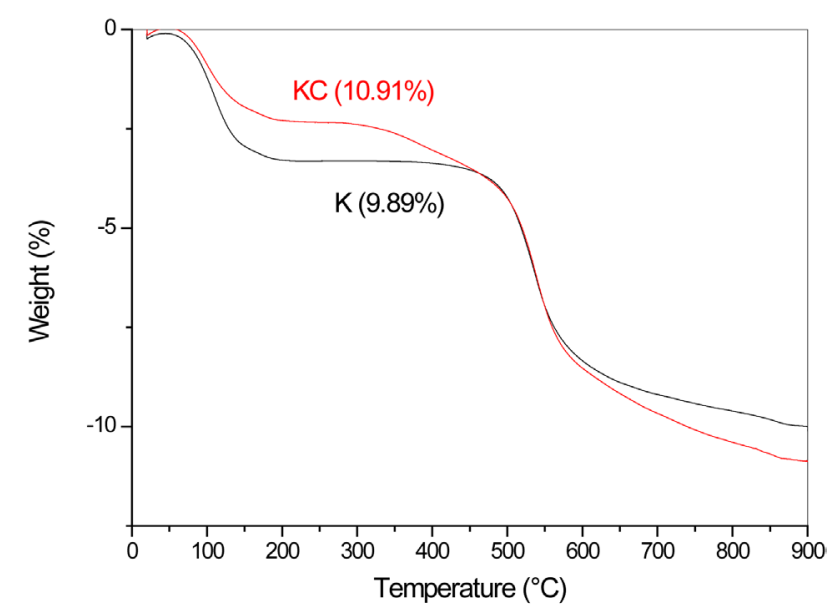

Figure 3. TG analysis of CTAB-kaolin (KC) and kaolin (K). 
$900^{\circ} \mathrm{C}$ due to both the elimination of coordinated water that become more strongly bonded to octahedral cations and the dehydroxylation of silanol [30].

The TG of CTAB-kaolin (KC) exhibited three stages of thermal decomposition. The first stage was due to adsorbed water and occurred over a temperature interval of $66^{\circ} \mathrm{C}-200^{\circ} \mathrm{C}$. The second stage was related to the coordinated water and the partial loss of organic moieties that were intercalated in the interlayer spacing over a temperature interval of $300^{\circ} \mathrm{C}-500^{\circ} \mathrm{C}$. The third loss over a temperature range of $500^{\circ} \mathrm{C}-900^{\circ} \mathrm{C}$ was due to the elimination of the organic groups and the dehydroxylation of the silanol groups on the clay surface. The data exhibited a significant alteration in the thermal degradation.

The typical hydrophilic character of $\mathrm{K}$ was modified after the reaction with surfactant, which was evident by the drastic difference between the percentages of the first mass loss. An additional change was the increase in the total mass loss, which values were $9.89 \%$ and $10.91 \%$ for $\mathrm{K}$ and $\mathrm{KC}$ respectively, as observed in Figure 3 .

\subsection{Effect of Contact Time}

As can be seen from the Figure 4, the adsorption rate of anionic dye in the first 10 min for KC is very fast. Highest amount of dye retained (98.16\%) is occurred within the initial 10minutes of contact time. After reaching the saturation value in 10 min of contact, a continuous and smooth curve is obtained for KC adsorbent. Based on these results, 10 min was taken as the equilibrium time in batch adsorption experiments on KC. The adsorption of CR on natural kaolin K occurred quickly from the beginning of the experiments during the first $10 \mathrm{~min}$, then a slight increase until 40 min where the maximum adsorption of CR was observed (64.24\%). Again as the results of this part of investigation clearly show, the uptake rate and adsorption amount of CR onto KC is much higher than that of $\mathrm{K}$ at any contact time. The difference in the equilibrium time for both adsorbents may be due to strong attractive forces such as electrostatic between the dye molecules and the surfactant-modified kaolin.

\subsection{Effect of $\mathrm{pH}$}

It was observed that the adsorption is highly dependent on the $\mathrm{pH}$ of the solution, which affects the surface charge of the adsorbent and the degree of ionization and speciation of the adsorbate. As evident from Figure 5, with increase in $\mathrm{pH}$ of the solution the amount adsorbed increases (this is due to the neutralization of the charges at the surface of the adsorbents) till $\mathrm{pH} 10$ but with further increase in the $\mathrm{pH}$, percentage adsorption drops in case of both adsorbents (K) and (KC). The high negatively charged adsorbents surface sites did not favour the adsorption of deprotonated CR due to electrostatic repulsion. Also, an abundance of $\mathrm{OH}^{-}$ions in basic solution creates a competitive environment with anionic ions of CR for the adsorption sites causing a decrease of adsorption [9] [31]. The high adsorption capacity of CTAB-kaolin is due to the strong electrostatic interaction between the $\mathrm{N}^{+}\left(\mathrm{CH}_{3}\right)_{3}$ and dye anions [32].

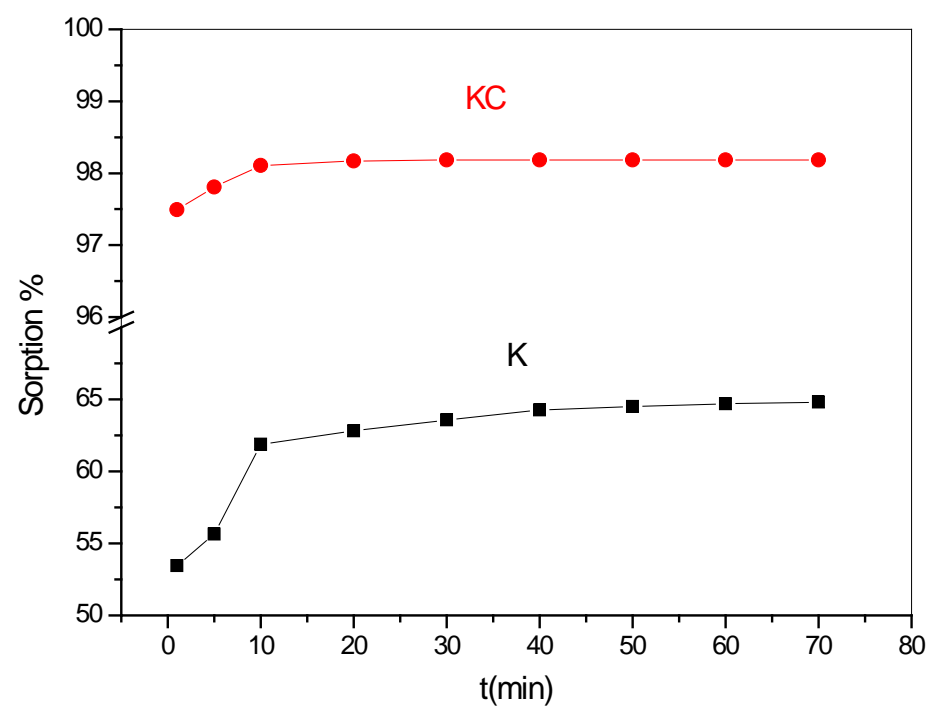

Figure 4. Effect of contact time of CR adsorption by K and KC. 


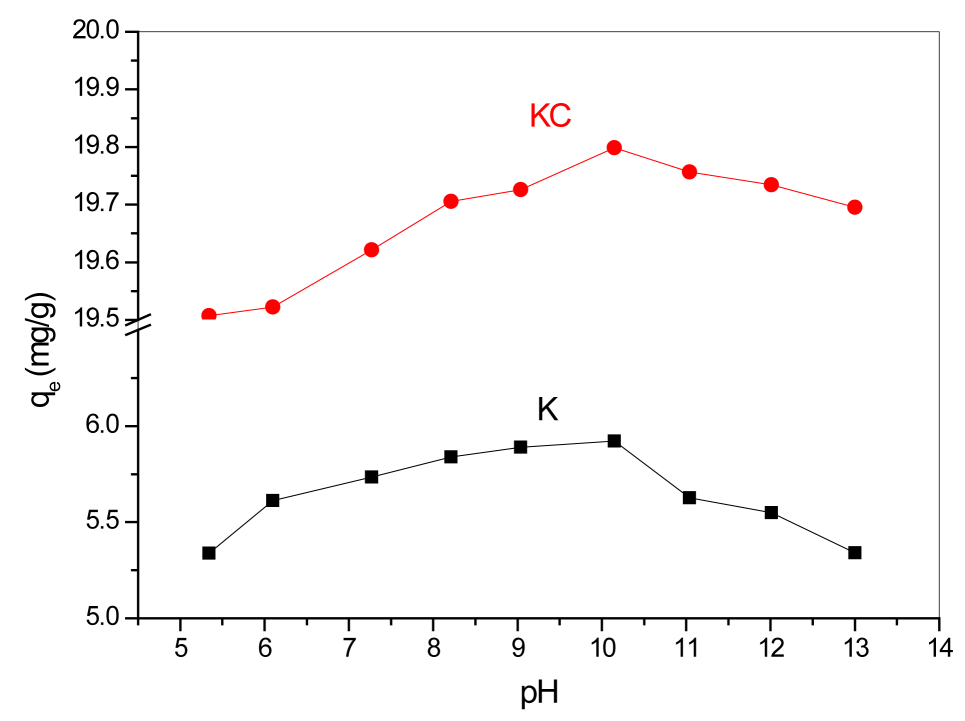

Figure 5. Effect of the $\mathrm{pH}$ on the $q_{e}$.

\subsection{Adsorption Isotherm Studies}

Several adsorption isotherm models have been employed to interpret the adsorption behaviors of dyes on solid adsorbents. In this study, the data collected have been fitted to the Langmuir isotherm [33] and the Freundlich isotherm [34], as described in Equations (4) and (5), respectively.

Langmuir equation

$$
\frac{C_{e}}{q_{e}}=\frac{C_{e}}{q_{m}}+\frac{1}{K_{L} q_{m}}
$$

Freundlich equation

$$
\ln q_{e}=\ln K_{f}+\left(\frac{1}{n}\right) \ln C_{e}
$$

In these equations, $C_{e}$ is the concentration of the dye in solution $(\mathrm{mg} / \mathrm{L})$ at equilibrium with the adsorbed dye, $q_{e}$ is the amount of the adsorbed dye (mg/g) at the solid/liquid interface, $q_{\max }$ is the monolayer capacity of the adsorbent $(\mathrm{mg} / \mathrm{g}), K_{\mathrm{L}}$ is the Langmuir adsorption constant $(\mathrm{L} / \mathrm{mg}), K_{f}$ and $1 / n$ are empirical parameters, $K_{f}$ is the adsorption constant related to the bonding energy and $1 / n$ is associated to the surface heterogeneity.

The adsorption isotherms of the dye onto K and KC were fitted by two models, as shown in Figure 6 and Figure 7. The parameters predicted by the two different models are summarized in Table 1. In general, parameters were fit using the linear adjustment, whereas the correlation coefficients were fit better using the Langmuir model. As the data clearly show adsorption capacity of surfactant modified kaolin (KC) for CR dye is considerably higher than natural kaolin (at least 4 times).

\subsection{Adsorption Kinetics}

Many models were used to describe the adsorption processes. The most appreciated was Pseudo-second-order (Equation (6)) [35].

As shown in Figure 8, the data corresponded to Pseudo-second-order well. The parameters of Pseudo-secondorder were listed in Table 2. The coefficients of determination $\left(R^{2}\right)$ for two materials were good.

$$
\frac{t}{q_{t}}=\frac{1}{2 k_{2} q_{e}^{2}}+\frac{1}{q_{e}} t
$$

where $q_{e}(\mathrm{mg} / \mathrm{g})$ and $q_{t}(\mathrm{mg} / \mathrm{g})$ are the adsorbed amounts of CR at equilibrium and time $t(\mathrm{~min}) ; k_{2}$ is the adsorption rate constants of Pseudo-second-order equation. 


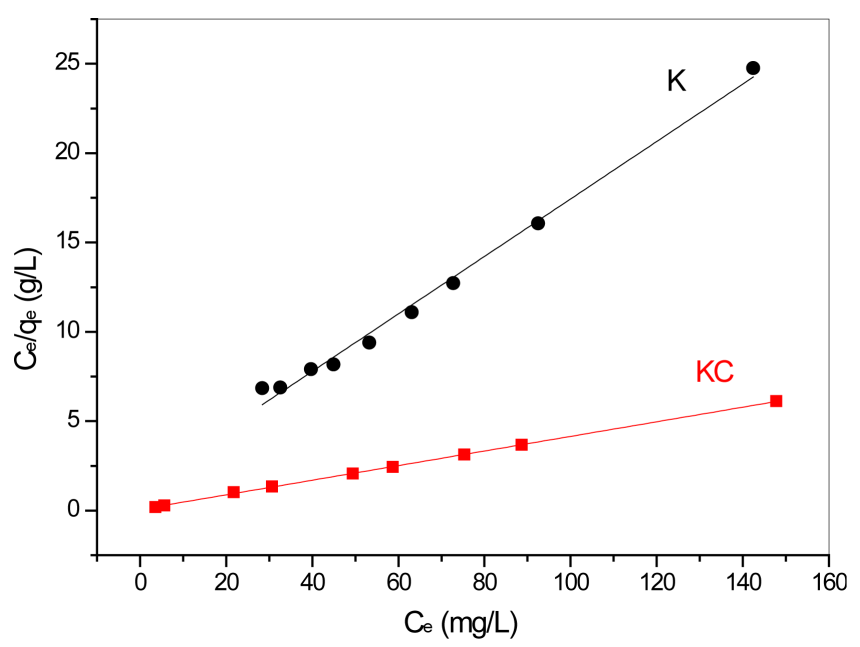

Figure 6. Langmuir linear plot for CR adsorption on K and KC.

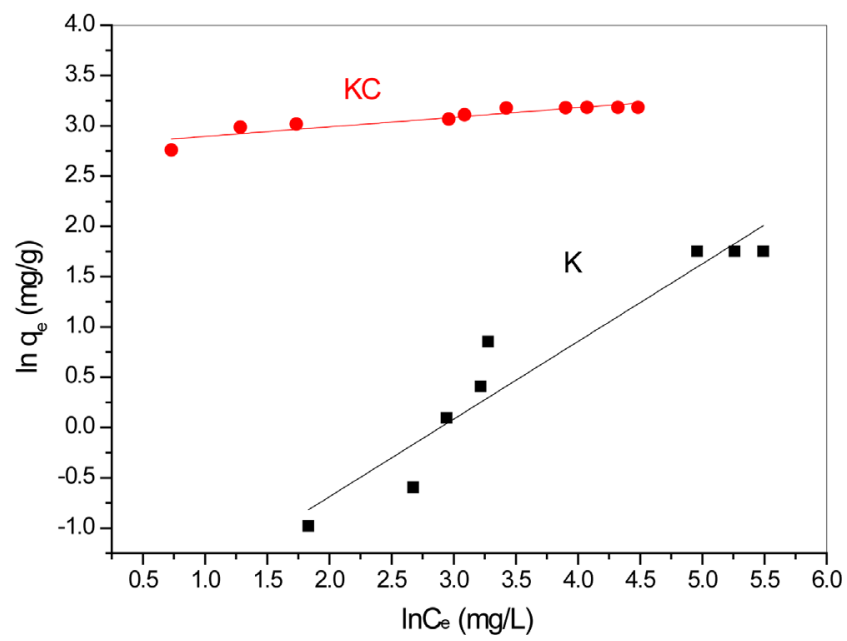

Figure 7. Freundlich linear plot for CR adsorption on K and KC.

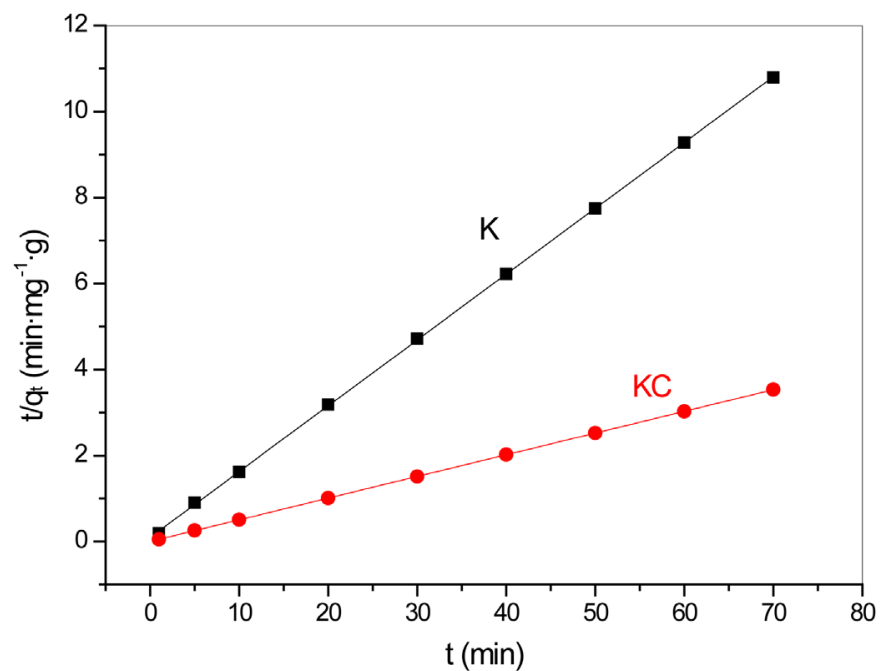

Figure 8. Pseudo-second-order parameters of CR adsorption onto kaolin (K) and modified kaolin (KC). 
Table 1. Langmuir and Freundlich isotherms for the adsorption of CR on K and KC.

\begin{tabular}{ccccccc}
\hline Adsorbent & \multicolumn{3}{c}{ Langmuir isotherm constants } & \multicolumn{3}{c}{ Freundlich isotherm constants } \\
\hline Parameters & $q_{m}(\mathrm{mg} / \mathrm{g})$ & $K_{L}(\mathrm{~L} / \mathrm{mg})$ & $R^{2}$ & $n$ & $K_{f}$ & $R^{2}$ \\
$\mathrm{~K}$ & 5.94 & 0.18 & 0.997 & 1.295 & 0.107 & 0.908 \\
$\mathrm{KC}$ & 24.46 & 1.52 & 0.999 & 10.51 & 16.43 & 0.834 \\
\hline
\end{tabular}

Table 2. Pseudo-second-order parameters of CR adsorption onto kaolin (K) and modified kaolin (KC).

\begin{tabular}{cccc}
\hline Sample & $k_{2}(\mathrm{~g} / \mathrm{mg} \cdot \mathrm{min})$ & $q_{e}(\mathrm{mg} / \mathrm{g})$ & $R^{2}$ \\
\hline $\mathrm{K}$ & 0.24 & 6.53 & 0.9999 \\
$\mathrm{KC}$ & 5.12 & 19.82 & 1 \\
\hline
\end{tabular}

\section{Conclusion}

The surface of natural kaolin is not a more effective adsorbent for the removal of hydrophobicorganic compounds from aqueous solution. This is due to the electrically charged and hydrophilic characteristics of the surface. However, natural kaolin maybe modified with large organic cations (CTAB) in a manner that significantly improves its capability of removing hydrophobic contaminants from water. Despite the introduction of organic ions into the interlayer spacing, the layered structure is maintained. CTAB-kaolin showed a higher adsorption capacity toward CR than kaolin. Kinetics data of adsorption were well fitted by the pseudo-second-order kinetic model, while the isotherm data were well represented by the Langmuir model. We thus conclude that the modified kaolin clay may be used as very effective adsorbent for removal of anionic toxic dyes from aqueous media.

\section{References}

[1] Gupta, V.K., Mittal, A., Krishnan, L. and Gajbe, V. (2004) Adsorption Kinetics and Column Operations for the Removal and Recovery of Malachite Green from Wastewater Using Bottom Ash. Separation and Purification Technology, 40, 87-96. http://dx.doi.org/10.1016/j.seppur.2004.01.008

[2] Tan, I.A.W., Ahmad, A.L. and Hameed, B.H. (2008) Adsorption of Basic Dye Using Activated Carbon Prepared from Oil Palm Shell: Batch and Fixed Bed Studies. Desalination, 225, 13-28. http://dx.doi.org/10.1016/j.desal.2007.07.005

[3] Attia, A., Badie, A., Girgis, S. and Nady, A. (2008) Removal of Methylene Blue by Carbons Derived from Peach Stones by $\mathrm{H}_{3} \mathrm{PO}_{4}$ Activation: Batch and Column Studies. Dyes and Pigments, 76, 282-289. http://dx.doi.org/10.1016/j.dyepig.2006.08.039

[4] Banat, I.M., Nigam, P., Singh, D. and Marchant, R. (1996) Microbial Decolorization of Textiledye-Containing Effluents: A Review. Bioresource Technology, 58, 217-227.

[5] Material Safety Data Sheet Congo Red MSDS. http://www.sciencelab.com/xMSDS-Congo_red-9927502

[6] Ghaedi, M., Hassanzadeh, A. and Nasiri Kokhdan, S. (2011) Multiwalled Carbon Nanotubes as Adsorbents for the Kinetic and Equilibrium Study of the Removal of Alizarin Red S and Morin. Journal of Chemical and Engineering, 56, 2511-2520.

[7] Yao, Z., Wang, L. and Qi, J. (2009) Biosorption of Methylene Blue from Aqueous Solution Using a Bioenergy Forest Waste: Xanthocerassorbifolia Seed Coat. Clean, 37, 642-648.

[8] Abd EI-Latif, M.M., Ibrahim, A.M. and EI-Kady, M.F. (2010) Adsorption Equilibrium, Kinetics and Thermodynamics of Methylene Blue from Aqueous Solutions Using Biopolymer Oak Sawdust Composite. Journal of American Science, 6, 267-283.

[9] Vimonses, V., Lei, S., Jin, B., Chow, C.W.K. and Saint, C. (2009) Kinetic Study and Equilibrium Isotherm Analysis of Congo Red Adsorption by Clay Materials. Chemical Engineering Journal, 148, 354-364. http://dx.doi.org/10.1016/j.cej.2008.09.009

[10] Sen, T.K., Afroze, S. and Ang, H.M. (2011) Equilibrium, Kinetics and Mechanism of Removal of Methylene Blue from Aqueous Solution by Adsorption onto Pine Cone Biomass of Pinus Radiate. Water, Air, Soil Pollution, 218, 499515. http://dx.doi.org/10.1007/s11270-010-0663-y

[11] Zenasni, M.A., Meroufel, B., Amrouche, A., Naâr, F., Merzouka, F. and Difallah, F. (2012) Phytoremédiation de Zn (II) par les racines de Calotropis Procera (Bechar, Algérie). ScienceLib, 4, 1-15. 
[12] Dawood, S. and Kanti Sen, T. (2012) Removal of Anionic Dye Congo Red from Aqueous Solution by Raw Pine and Acid-Treated Pine Cone Powder as Adsorbent: Equilibrium, Thermodynamic, Kinetics, Mechanism and Process Design. Water Research, 46, 1933-1946. http://dx.doi.org/10.1016/j.watres.2012.01.009

[13] Zenasni, M.A., Benfarhi, S., Mansri, A., Benmehdi, H., Meroufel, B., Desbrieres, J. and Dedriveres, R. (2011) Influence of $\mathrm{pH}$ on the Uptake of Toluene from Water by the Composite Poly(4-vinylpyridinium)-Maghnite. African Journal of Pure and Applied Chemistry, 5, 486-493. http://dx.doi.org/10.5897/AJPAC11.066

[14] Sharma, Y.C. (2010) Optimization of Parameters for Adsorption of Methylene Blue on a Low-Cost Activated Carbon. Journal of Chemical \& Engineering Data, 55, 435-439.

[15] Wang, S., Zhu, Z.H., Coomes, A., Haghseresht, F. and Lu, G.Q. ( 2005) The Physical and Surface Chemical Characteristics of Activated Carbons and the Adsorption of Methylene Blue from Wastewater. Journal of Colloid and Interface Science, 284, 440-446. http://dx.doi.org/10.1016/j.jcis.2004.10.050

[16] Zenasni, M.A., Benfarhi, S., Merlin, A., Molina, S., George, B. and Meroufel, B. (2012) Adsorption of Cu(II) on Maghnite from Aqueous Solution: Effects of $\mathrm{pH}$, Initial Concentration, Interaction Time and Temperature. Natural Science, 4, 856-868. http://dx.doi.org/10.4236/ns.2012.411114

[17] Salleh, M.A.M., Mahmoud, D.K., Karim, W.A. and Idris, A. (2011) Cationic and Anionic Dye Adsorption by Agricultural Solid Wastes: A Comprehensive Review. Desalination, 280, 1-13. http://dx.doi.org/10.1016/j.desal.2011.07.019

[18] Meroufel, B., Benali, O., Benyahia, M., Benmoussa, Y. and Zenasni, M.A. (2013) Adsorptive Removal of Anionic Dye from Aqueous Solutions by Algerian Kaolin: Characteristics, Isotherm, Kinetic and Thermodynamic Studies. Journal of Materials and Environmental Science, 4, 482-491.

[19] Quintelas, C., Figueiredo, H. and Tavares, T. (2011) The Effect of Clay Treatment on Remediation of Diethylketone Contaminated Wastewater: Uptake, Equilibrium and Kinetic Studies. Journal of Hazardous Materials, 186, 1241-1248. http://dx.doi.org/10.1016/j.jhazmat.2010.11.131

[20] Akcay, M. (2004) Characterization and Determination of the Thermodynamic and Kinetic Properties of p-CP Adsorption onto Organophilic Bentonite from Aqueous Solutions. Journal of Colloid and Interface Science, 280, $299-304$. http://dx.doi.org/10.1016/j.jcis.2004.07.030

[21] Silva, M., Oliveira, M., Avelino, M., Fonseca, M., Almeida, R. and Silva Filho, E. (2012) Adsorption of an Industrial Anionic Dye by Modified-KSF-Montmorillonite: Evaluation of the Kinetic, Thermodynamic and Equilibrium. Chemical Engineering Journal, 203, 259-268. http://dx.doi.org/10.1016/j.cej.2012.07.009

[22] Shakir, K., Ghoneimy, H.F., Elkafrawy, A.F., Beheir, Sh.G. and Refaat, M. (2008) Removal of Catechol from Aqueous Solutions by Adsorption onto Organophilic-Bentonite. Journal of Hazardous Materials, 150, 765-773. http://dx.doi.org/10.1016/j.jhazmat.2007.05.037

[23] Unuabonah, E.I., Olu-Owolabi, B.I., Adebowale, K.O. and Ofomaja, A.E. (2007) Adsorption of Lead and Cadmium Ions from Aqueous Solutions by Tri-Polyphosphate Impregnated Kaolinite Clay. Colloids and Surfaces A: Physicochemical and Engineering Aspects, 292, 202-211. http://dx.doi.org/10.1016/j.colsurfa.2006.06.024

[24] Adebowale, K.O., Unuabonah, I.E. and Olu-Owolabi, B.I. (2008) Kinetic and Thermodynamic Aspects of the Adsorption of $\mathrm{Pb}^{2+}$ and $\mathrm{Cd}^{2+}$ Ions on Tripolyphosphate-Modified Kaolinite Clay. Chemical Engineering Journal, 136, 99-107. http://dx.doi.org/10.1016/j.cej.2007.03.012

[25] Manohar, D.M., Anoop, K.K. and Anirudan, T.S. (2002) Removal of Mercury (II) from Aqueous Solutions and Chloro-Alkali Industry Wastewater Using 2-Mercaptobenzimidazole Clay. Water Research, 36, 1609-1619. http://dx.doi.org/10.1016/S0043-1354(01)00362-1

[26] Safa Özcan, A., Erdem, B. and Özcan, A. (2004) Adsorption of Acid Blue 193 from Aqueous Solutions onto Na-Bentonite and DTMA-Bentonite. Journal of Colloid and Interface Science, 280, 44-54. http://dx.doi.org/10.1016/j.jcis.2004.07.035

[27] Zenasni, M.A., Benfarhi, S., Merlin, A., Molina, S., George, B. and Meroufel, B. (2013) Adsorption of Nickel in Aqueous Solution onto Natural Maghnite. Materials Sciences and Applications, 4, 153-161.

[28] Meroufel, B., Benali, O., Benyahia, M., Zenasni, M.A., Merlin, A. and George, B. (2013) Removal of Zn(II) from Aqueous Solution onto Kaolin by Batch Design. Journal of Water Resource and Protection, 5, 669-680.

[29] Madejova, J. (2003) FTIR Techniques in Clay Mineral Studies. Vibrational Spectroscopy, 31, 1-10. http://dx.doi.org/10.1016/S0924-2031(02)00065-6

[30] Yariv, S., Borisover, M. and Lapides, I. (2011) Few Introducing Comments on the Thermal Analysis of Organoclays. Journal of Thermal Analysis and Calorimetry, 105, 897-906. http://dx.doi.org/10.1007/s10973-010-1221-y

[31] Namasivayam, C. and Kavitha, D. (2002) Removal of Congo Red from Water by Adsorption onto Activated Carbon Prepared from Coir Pith, an Agricultural Solid Waste. Dyes and Pigments, 54, 47-58. http://dx.doi.org/10.1016/S0143-7208(02)00025-6 
[32] Yoshida, H., Okamoto, A. and Kataoka, T. (1993) Adsorption of Acid Dye on Cross-Linked Chitosan Fibers: Equilibria. Chemical Engineering Science, 48, 2267-2272. http://dx.doi.org/10.1016/0009-2509(93)80242-I

[33] Langmuir, I. (1918) The Adsorption of Gases on Plane Surfaces of Glass, Mica and Platinum. Journal of the American Chemical Society, 40, 1361-1403. http://dx.doi.org/10.1021/ja02242a004

[34] Freundlich, H.M.F. (1906) Uber Die Adsorption in Losungen. Zeitschrift fur Physikalische Chemie, 57, 385-470.

[35] Ho, Y.S. (2004) Selection of Optimum Sorption Isotherm. Carbon, 42, 2115-2116. http://dx.doi.org/10.1016/j.carbon.2004.03.019 
Scientific Research Publishing (SCIRP) is one of the largest Open Access journal publishers. It is currently publishing more than 200 open access, online, peer-reviewed journals covering a wide range of academic disciplines. SCIRP serves the worldwide academic communities and contributes to the progress and application of science with its publication.

Other selected journals from SCIRP are listed as below. Submit your manuscript to us via either submit@scirp.org or Online Submission Portal.
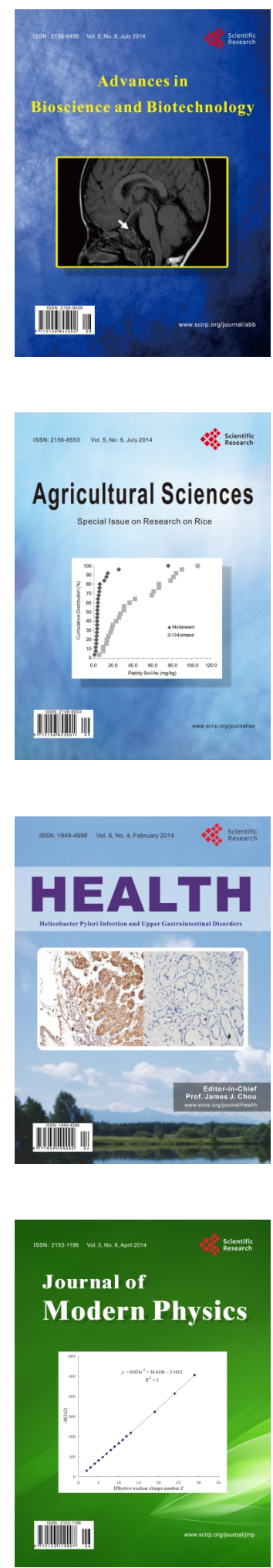
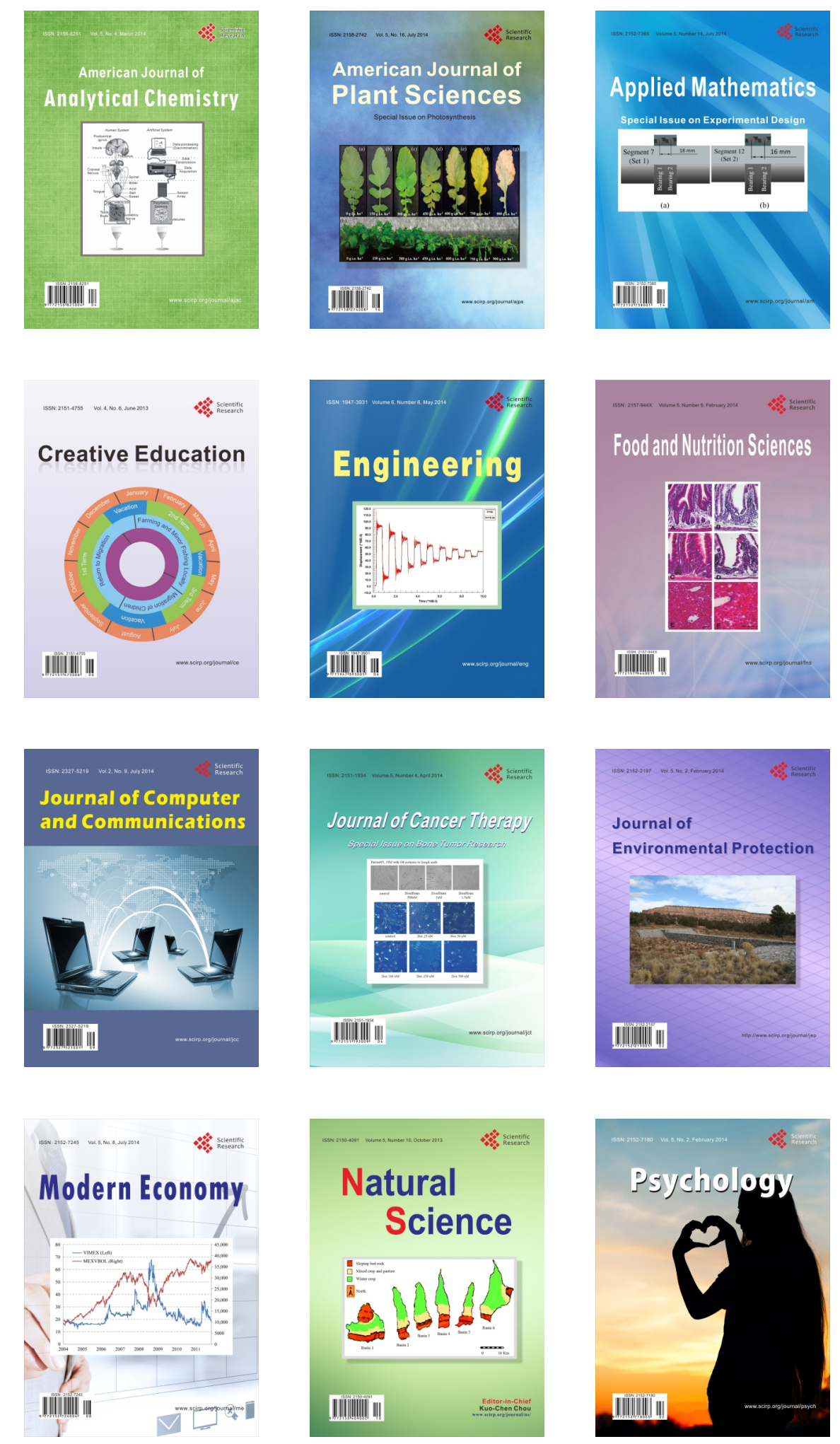